\title{
THE EFFECT OF THE THERMODYNAMIC MODELS ON THE THERMOECONOMIC RESULTS FOR COST ALLOCATION IN A GAS TURBINE COGENERATION SYSTEM
}

\author{
R. G. dos Santos ${ }^{\mathrm{a}}$, \\ P. R. de Fariab \\ J. J. C. S. Santos ${ }^{c}$, \\ J. A. M. da Silva ${ }^{d}$, \\ and J. L. M. Donatellic \\ ${ }^{a}$ Federal Institute of Espírito Santo- IFES \\ Piúma, Brazil \\ rodrigo.guedes@ifes.edu.br \\ ${ }^{\mathrm{b}}$ East Center College - UCL \\ Serra, Brazil \\ pedrorosseto@ucl.br \\ ${ }^{c}$ Federal University of Espírito Santo - UFES \\ Vitória, Brazil \\ ${ }^{\mathrm{d}}$ Federal University of Bahia - UFBA \\ Salvador, Brazil \\ Received: October 28, 2015 \\ Revised: November 14, 2015 \\ Accepted: December 04, 2015

\section{NOMENCLATURE \\ c Monetary Unit Cost [\$/kWh] \\ $k \quad$ Exergetic Unit Cost [kW/kW] \\ $Q \quad$ Heat Exergy [kW] \\ $Y \quad$ Generic Productive Flow [kW] \\ Z Hourly Cost [\$/h]}

\section{Subscripts \\ in Inlet \\ out Outlet \\ F $\quad$ Fuel}

\section{ABSTRACT}

The thermoeconomics combines economics and thermodynamics to provide information not available from conventional energy and economic analysis. For thermoeconomics modeling one of the keys points is the thermodynamic model that should be adopted. Different thermodynamic models can be used in the modeling of a gas turbine system depending on the accuracy required. A detailed study of the performance of gas turbine would take into account many features. These would include the combustion process, the change of composition of working fluid during combustion, the effects of irreversibilities associated with friction and with pressure and temperature gradients and heat transfer between the gases and walls. Owing to these and others complexities, the accurate modeling of gas turbine normally involves computer simulation. To conduct elementary thermodynamic analyses, considerable simplifications are required. Thus, there are simplified models that lead to different results in thermoeconomics. At this point, three questions arise: How different can the results be? Are these simplifications reasonable? Is it worth using such a complex model? In order to answer these questions, this paper compares three thermodynamic models in a gas turbine cogeneration system from thermoeconomic point of view: cold air-standard model, CGAM model and complete combustion with excess air.

Keywords: thermoeconomics, thermodynamic modeling

\section{INTRODUCTION}

Thermoeconomics can be considered a new science which, by connecting Thermodynamics and Economics, provides tools to solve problems in complex energy systems that can hardly or not be solved using conventional energy analysis techniques based on First Law of Thermodynamics (mass and energy balance), as for instance a rational price assessment to the products of a plant based on physical criteria (Erlach et al., 1999).

Various methodologies were proposed in the last 25 years and all of them have in common a cost calculated on a rational basis, which is by using the Second Law of Thermodynamics (Serra and Torres, 2003). However, the choice of the best residue distribution criteria among possible alternatives is still an open research line. Different thermoeconomic methodologies can provide different cost values depending on the way they define de product/fuels of each subsystem of the plant and the criteria for the residue cost allocation to the final products. One of the keys points at thermoeconomics modeling is to decide which thermodynamic model should be adopted. Different thermodynamic models can be used in the modeling of the gas thermal system depending on the accuracy required. A detailed study of the performance of gas turbine would take into account many features. These would include the combustion process, the change of composition of the working fluid during combustion, the effects of irreversibilities associated with friction and with pressure, temperature gradients and heat transfer 
between the gases and walls. Owing to these and others complexities, the accurate modeling of gas turbine normally involves computer simulation. To conduct elementary thermodynamic analyses, considerable simplifications are required. Thus, there are simplified models that lead to different results in thermoeconomics.

This study examined a cogeneration plant with gas turbine presented on the well-known CGAM problem and will compare the exergetic cost given by the thermoeconomic analysis using the different thermodynamic models.

\section{PHYSICAL STRUCTURE}

The cogeneration plant delivers 30 MW of electricity and $14 \mathrm{~kg} / \mathrm{s}$ of saturated steam at $20 \mathrm{bar}$ (Valero et al., 1994a). The structure of the cogeneration plant is shown in Fig. 1. The installation consists of a regenerative gas turbine with a heatrecovery steam generator, in which the required steam is produced. The environmental conditions are defined as T0 (298.15K), $\mathrm{P}_{0}$ (1,013 bar) and relative humidity (60\%). The fuel for the plant is natural gas (taken as methane) with a lower heating value (LHV) equal to $50,000 \mathrm{~kJ} / \mathrm{kg}$ and specific exergy equal to $51,850 \mathrm{~kJ} / \mathrm{kg}$.

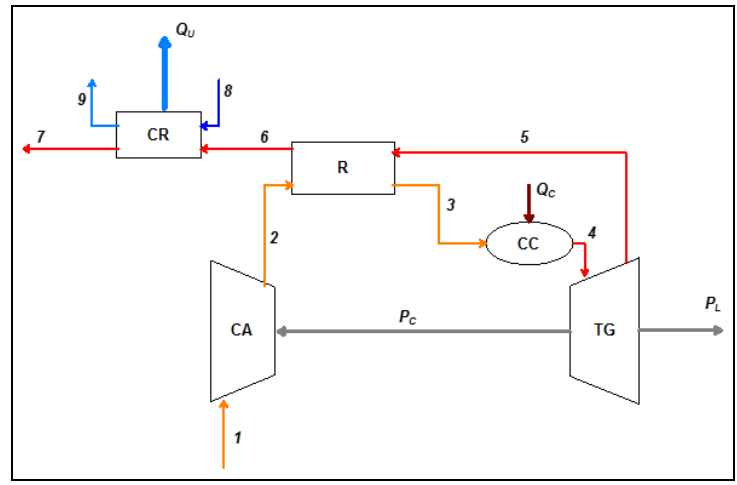

Figure 1. Flow diagram of the cogeneration system.

All components, except for the combustion chamber, are adiabatic. Reasonable values are chosen for the pressure loss of the air and gas flows in the combustion chamber, air preheater and recovery boiler. Thus, thermodynamic properties are showed in Tab. 1.

Table 1 Main flow parameters.

\begin{tabular}{|c|c|c|}
\hline Flow & $\mathrm{p}[\mathrm{bar}]$ & $\mathrm{T}[\mathrm{K}]$ \\
\hline 1 & 1.013 & 298.15 \\
\hline 2 & 8.634 & - \\
\hline 3 & 8.202 & 914.28 \\
\hline 4 & 7.792 & 1492.63 \\
\hline 5 & 1.099 & - \\
\hline 6 & 1.066 & - \\
\hline 7 & 1.013 & - \\
\hline 8 & 20 & 298.15 \\
\hline 9 & 20 & 485.52 \\
\hline
\end{tabular}

Few temperatures values that will be calculated depending of the thermodynamic model were replaced by “-”.

The remaining design parameters considered in all models are: the isentropic efficiency of the air compressor $\left(\eta_{\mathrm{AC}}=84.68 \%\right)$ and the isentropic efficiency of the gas turbine $\left(\eta_{\mathrm{GT}}=87.86 \%\right)$.

\section{THERMODYNAMIC MODELS}

Although the physical structure is the same for all cases, the thermodynamic model for each one is different. This study worked with: cold air-standard model, CGAM model and complete combustion model.

\section{Cold air-standard model}

Assumptions made for these modeling are: (i) A fixed amount of air modeled as an ideal gas is the working fluid. (ii) The combustion process is replaced by a heat transfer from an external source. (iii) the specific heat is assumed constant $(\mathrm{Cp}=1.004$ $\mathrm{kJ} / \mathrm{kgK}$ and $\mathrm{k}=1.4$ ) at ambient temperature values. Although an air-standard analysis simplifies the study considerably, values for the mean effective pressure and operating temperatures and pressures calculated on this basis may depart significantly from those of actual engines. Accordingly, air-standard analysis allows the study to be examined only qualitatively. Still, insights concerning actual performance can result with such an approach (Moran and Shapiro, 2011).

\section{CGAM model}

To simplify this model without loss of methodological generality, the following assumptions are made (Valero et al, 1994b): (i) The air and the combustion gases behave as ideal gases with constant specific heats. However, the $\mathrm{Cp}$ values are different for air $(\mathrm{Cp}=1.004 \mathrm{~kJ} / \mathrm{kgK}$ and $\mathrm{k}=1.4)$ and gases $(\mathrm{Cp}=1.17 \mathrm{~kJ} / \mathrm{kgK}$ and $\mathrm{k}=1.33)$. For combustion calculations, the fuel is taken to be methane $\left(\mathrm{CH}_{4}\right)$. This model considers the amount of fuel, i.e., the gases mass flow is greater than the air mass flow.

\section{Complete combustion model}

The air and the combustion gases are considered as mixtures of ideal gases $\left(\mathrm{O}_{2}, \mathrm{~N}_{2}, \mathrm{CO}_{2}, \mathrm{H}_{2} \mathrm{O}\right.$ and $\mathrm{Ar})$. Their specific heat varies with temperature according to a polynomial equation. The molar compositions of the air and combustion gases streams are estimated considering excess air. (Santos, 2008b)

\section{THERMOECONOMIC MODELING}

The thermoeconomic model is a set of equations which describes the cost formation process of the 
system. To carry out a thermoeconomic analysis, it is convenient to make up a thermoeconomic model, which define the productive propose of the subsystems (products and fuels), as well as the distribution of the external resources and internal product throughout the system. The way in which the productive structure is defined is a key point in thermoeconomic analysis. In other words, the deeper the conceptual disaggregation of the system in components and flows, the better the results (Lozano and Valero, 1993). Given the flow sheet or the physical structure of an energy system (Fig. 1, in this case), it is possible to define the productive structure. All thermoeconomic methodologies require the productive structure definition, which can be represented by means of the productive diagram. The only limitation with must be imposed is that it should be possible to evaluate all the flows of the productive structure in relation to the state of the plant as defined by the physical structure (Lozano and Valero, 1993). At this point, it should be mentioned that not all the methodologies need to represent the productive structure by means of a productive diagram (SPECO, in this case). However, the other thermoeconomic models analyzed in this work is based on the productive diagrams, which offers the advantage of showing clearly and graphically how the product of a given subsystem is distributed so that it can be used as an input to another subsystem or as a final product.

$\sum\left(c_{\text {out }} \cdot Y_{\text {out }}\right)-\sum\left(c_{\text {in }} \cdot Y_{\text {in }}\right)=Z+c_{F} \cdot Q_{F}$

In order to calculate the monetary unit cost of each internal productive flow and final products, the mathematical model for cost allocation which is a set of cost equations obtained by formulating cost equation balance in each subsystem of the productive diagram, as shown in Eq. (1), should be used. The solution of these set of equation is the monetary unit costs of each internal productive flow and each final product. The monetary unit cost of a flow is the amount of monetary unit required to obtain one unit of this flow, i.e., it is a measure of the economic efficiency of the production process generating this flow. In Eq. (1), $\mathrm{c}_{\text {out }}$ and $\mathrm{c}_{\text {in }}$ are unknown variables representing the monetary unit cost of the internal flows at the outlet and the inlet of the subsystems, respectively; $\mathrm{Y}_{\text {out }}$ and $\mathrm{Y}_{\text {in }}$ represent the generic internal productive flow (in $\mathrm{kW}$ ) at inlet and outlet of the subsystems, respectively, which can be assessed using any thermodynamic magnitude, such as, power $(P)$, total exergy $(E)$, negentropy $(S)$, enthalpy $(H)$, etc. The Fig. 2 summarizes the thermodynamics magnitudes used by the thermoeconomic models.

$\mathrm{Z}$ represents the external hourly cost of the subsystem due to the capital cost, operation and maintenance cost of the equipment (in $\$ / h$ ); $\mathrm{c}_{\mathrm{F}}$ is a known market unit cost of the external fuel exergy (in $\$ / \mathrm{kWh}$ ) and $\mathrm{Q}_{\mathrm{F}}$ is the plant external exergy consumption (in $\mathrm{kW}$ ). Since the number of internal productive flows is always greater than the number of subsystems or units, auxiliary equations are required.

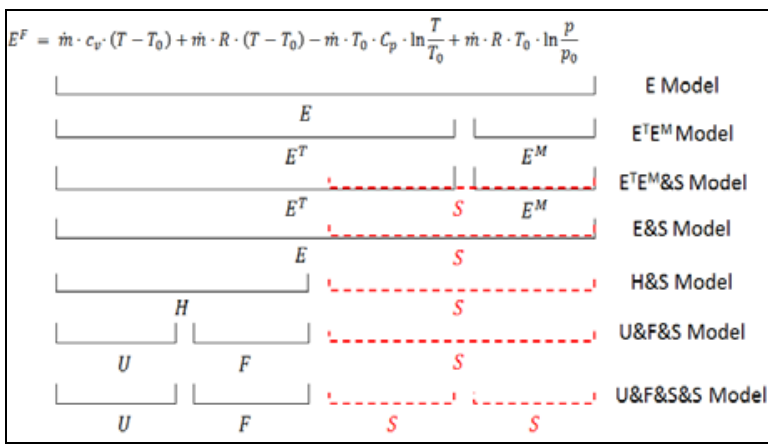

Figure 2. The thermodynamic magnitudes used by the thermoeconomic models

For the thermoeconomic models based on productive diagram, there are two different ways to obtain these auxiliary equations: the Sub-product (SP) and the Multi-product (MP) criteria. Subproduct criterion considers that each plant subsystem can have only one product or main function. Thus, the others internal productive flows exiting the subsystem are byproducts. Therefore, the Subproduct assumes the same unit cost as the product of others subsystems that produce only this kind of productive internal flows. The Multi-product criterion considers that all internal productive flows exiting the same subsystem are all products, which must have the same unit cost, since they were produced under the same resources and irreversibility. For the thermoeconomic models based on physical structure, the criteria for auxiliary equations are the fuel and product principle. According to the fuel principle it is considered that a component uses a part of inlet flow to produce a given product. Thus, the remaining part of the inlet flow (which is one of the outlet flows) carries the same unit cost of the inlet flow. On the other hand, the product principle considers that all the outlet flows have same unit cost.

$$
\sum\left(k_{\text {out }} \cdot Y_{\text {out }}\right)-\sum\left(k_{\text {in }} \cdot Y_{\text {in }}\right)=k_{F} \cdot Q_{F}
$$

By modifying Eq. (1) so as to formulate the cost balances to provide the exergetic unit cost $\left(\mathrm{k}_{\text {out }}\right.$ and $\mathrm{k}_{\text {in }}$ ) of each productive flow of the productive structure, Eq. (2) is obtained. The exergetic unit cost of a flow (in $\mathrm{kW} / \mathrm{kW}$ ) is the amount of exergy required to obtain one exergy unit of this flow. This cost is a measure of the thermodynamic efficiency of the production process generating this flow. In this case, the hourly cost of the subsystem due to the capital cost, operation and maintenance must be zero $(\mathrm{Z}=0)$ and the monetary unit cost of the external fuel exergy is replaced by the exergetic unit cost of the external fuel exergy, which is $1.00 \mathrm{~kW} / \mathrm{kW}$, since it is considered that there is no exergy destruction before the productive process is performed. The auxiliary 
equations and the productive internal flows and final products remain the same as used for the monetary unit cost. Although this methodology was here presented taking into account the thermoeconomic models based on the productive diagram, the same concept and procedure can be used for physical structure too.

\section{Using Physical Structure}

Thermoeconomic modeling based on physical structure and flows is a characteristic of the Exergoeconomics methodologies (AVECO and LIFO) by Tsatsaronis and Pisa (1994) unified recently by SPECO (Lazzaretto and Tsatsaronis, 2006).

\section{Using Productive Structure}

To describe the process of cost formation in thermal systems based on productive flows is originally a characteristic of Functional Methodologies: Thermoeconomic Functional Approach - TFA (Frangopoulos, 1994) and Engineering Functional Analysis - EFA (von Spakovsky, 1994). The productive structure offers the advantage of showing clearly and graphically how the product of a given subsystem is distributed to be used as input in another subsystem or as a final product of the plant.

\section{E Model}

The E Model utilizes total exergy without any disaggregation.

\section{$\mathbf{E}^{\mathrm{T}} \boldsymbol{\&} \mathbf{E}^{\mathrm{M}}$ Model}

This model consists in the disaggregation of physical exergy flows into their thermal $\left(\mathrm{E}_{\mathrm{i}: \mathrm{j}}^{\mathrm{T}}\right)$ and mechanical $\left(\mathrm{E}_{\mathrm{i}: \mathrm{j}}^{\mathrm{M}}\right)$ components. Its productive structure is equivalent to that of the CGAM plant introduced by Frangopoulos (1994) and used by Torres et al. (1996).

According to Thermoeconomic Functional Approach - TFA (Frangopoulos, 1994), the air compressor produces all mechanical exergy used by the others equipment in the system. The air compressor also produces thermal exergy, which justify the existence of the small circle indicating that its product has multiple output streams. The main consideration in TFA is that all products of a given productive unit have the same unit cost. Disaggregation of exergy in their thermal and mechanical components is also used by the structural version of the Exergetic Cost Theory (Lozano et al., 1993). In its theory, the Structural Analysis Approach (SAA), introduced the concept of byproduct. The exergy thermal component produced by the air compressor is considered as a byproduct, because the air compressor function is to produce mechanical and not thermal exergy. The temperature increase (thermal exergy) is considered a mere consequence of mechanical exergy increase.

To differentiate the product and byproduct cost, the SAA proposes a new rule for the auxiliary equations: the byproduct (thermal exergy) should has the same unit cost of the thermal exergy produced by the combustion chamber, which is the only equipment whose function is to produce thermal exergy.

\section{E\&S Model}

The negentropy flow has been used together with the exergy flow as a fictitious flow (E\&S Model) by three known thermoeconomic methodologies: Thermoeconomic Functional Analysis (Frangopoulos, 1987), Structural Theory of Thermoeconomics (Lozano et al., 1993) and Engineering Functional Analysis (von Spakovsky, 1994).

\section{$\mathbf{E}^{\mathrm{T}} \& \mathbf{E}^{\mathrm{M}} \& \mathrm{~S}$ Model}

This model considers the characteristics of both, $\mathrm{E}^{\mathrm{T}} \& \mathrm{E}^{\mathrm{M}}$ and $\mathrm{E} \& \mathrm{~S}$ Models, seeing that it uses exergy flows together with the negentropy flows as E\&S Model. However, the physical exergy is disaggregated into their thermal and mechanical components as in the $\mathrm{E}^{\mathrm{T}} \& \mathrm{E}^{\mathrm{M}}$ Model.

Once that the use of exergy together with the negentropy is a characteristic of the Structural Analysis Approach (SSA), it uses the concept of byproduct, as explained in sections $\mathrm{E}^{\mathrm{T}} \& \mathrm{E}^{\mathrm{M}}$ Model and E\&S Model.

Thermoeconomic Functional Approach (TFA) also uses negentropy together with the exergy disaggregated in their thermal and mechanical components (Frangopoulos, 1987). In this case, however,it has no byproducts, i.e., all outlet flows exiting the same subsystem have the same unit cost. This concept is used for the compressor and the recovery boiler outlet flows. In other words, in this paper the $\mathrm{E}^{\mathrm{T}} \& \mathrm{E}^{\mathrm{M}} \& \mathrm{~S}$ Model is applied according to SAA and also according TFA.

\section{H\&S Model}

This model defines the productive diagram by disaggregating the physical exergy into enthalpic and entropic components. Santos et al. (2006) introduced this kind of physical exergy disaggregation.

\section{U\&F\&S Model}

This model utilizes physical exergy disaggregated into internal energy (U), work flow (F) and entropic term (S), Lourenço et al. (2011). It was the first kind of exergy disaggregation capable to 
isolate valves.

\section{U\&F\&S\&S Model}

This Model is an extension of U\&F\&S. It maintains internal energy (U), work flow (F) components while the entropic term (S) is disaggregated into its thermal and mechanical components.

\section{RESULTS AND CLOSURE}

Fig. 3, 4, 5 and 6 represent the results of this work. Given the cogeneration plant (flow sheet and physical model) equipment and fuel costs, external parameters can be directly obtained: net power, useful heat exergy and fuel exergy. The challenge of cost allocation models is to determine the exergetic and monetary unit cost of net power and useful heat exergy. No matter the allocation method, the result will be unavoidably a pair unit cost for both final products along a defined straight line. Thus, the higher the unit cost of heat, the lower the unit cost of power and vice versa.

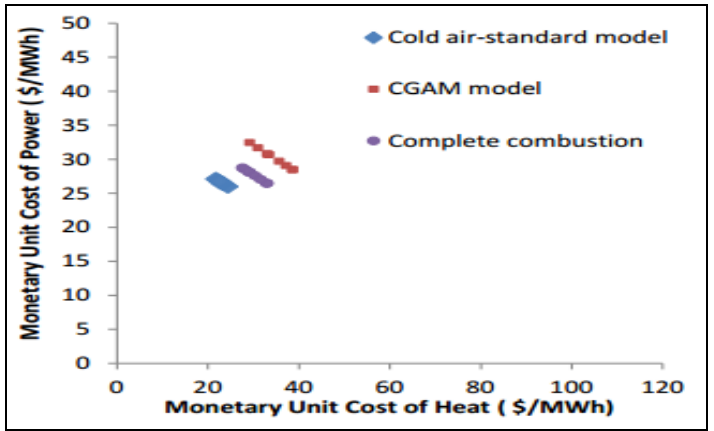

Figure 3. Monetary unit cost of heat exergy and power obtained by using different thermodynamics models.

No matter the kind of cogeneration plant, if the heat power ratio and the overall exergetic efficiency is the same, the straight line will be unavoidably the same.

If the heat power ratio is the same and the overall exergetic efficiency is different, the straight lines will be parallel each another. This is the case in this work.

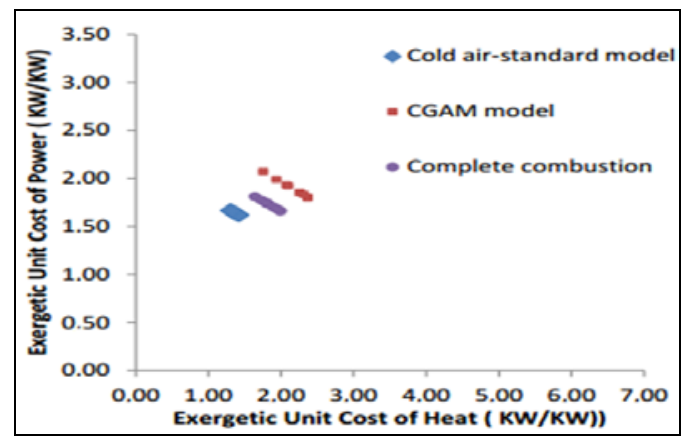

Figure 4. Exergetic unit cost of heat exergy and power obtained by using different thermodynamics models.

Fig. 5 and 6 compare the exergetic and monetary unit cost, respectively, of heat exergy and power obtained by using different thermodynamics models as well as different thermoeconomic methodologies. For the same thermoeconomic model, each thermodynamic model presents a different value for the unit cost of power and heat exergy. This is due different exergetic efficiency of the overall plant. Since the equipment costs and fuel unit cost of the plant are the same for all thermodynamics and thermoeconomic models, for the same thermoeconomic model, the higher the overall exergetic efficiency, the lower the unit cost the final products (heat exergy and power). CGAM Model has the lower overall exergetic efficiency and the cold air-standard Model has the higher one.

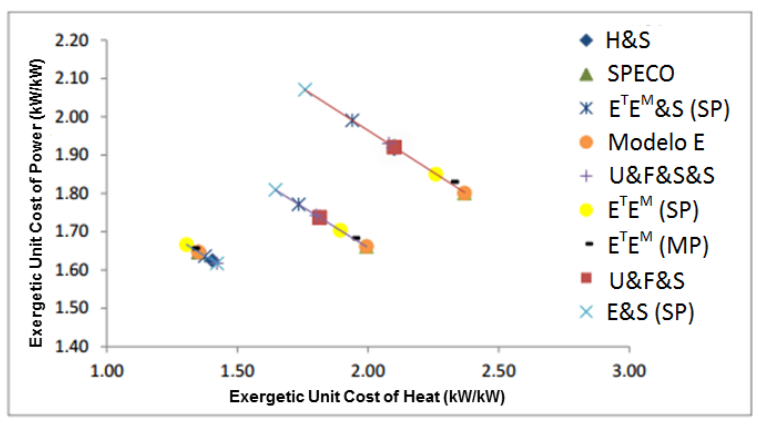

Figure 5. Exergetic unit cost of heat and power obtained by using different models and thermodynamics models.

The complete combustion model can be considered as the more accurate result, since it has less simplifying assumptions.

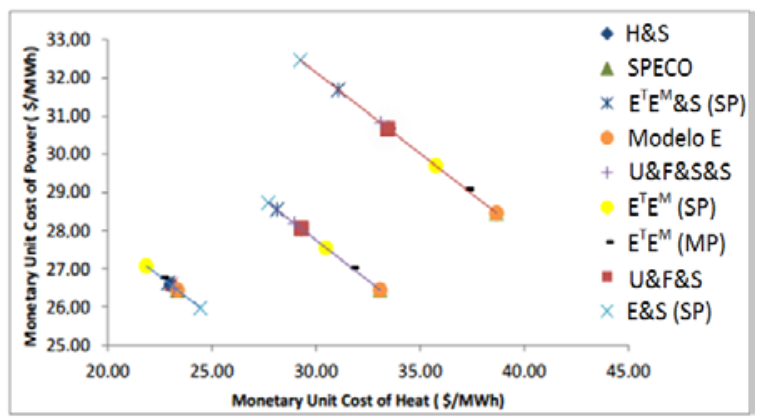

Figure 6. Monetary unit cost of heat and power obtained by using different models and thermodynamics models.

Qualitatively comparing the thermoeconomic approaches for each thermodynamic model, the results are almost the same for CGAM and complete combustion models. However the cold air-standard 
model generated different results. This difference lies on the mass flow of the natural gas that was not considered as well as on not considering the increase of Cp with temperature.

\section{ACKNOWLEDGEMENTS}

The authors acknowledge with gratitude the support of the Program of Human Resources for the Oil Sector and Natural Gas, of the Brazilian Oil National Agency - PRH-ANP and the PPGEM-UFES for the opportunity.

\section{REFERENCES}

Frangopoulos, C. A., 1994, Application of the Thermoeconomic Functional Approach to the CGAM Problem, Energy Vol. 19, No. 3, pp. 323-342.

Frangopoulos, C.A., 1987, Thermo-Economic Functional Analysis and Optimization, Energy, Vol. 12, No. 7, pp. 563-571.

Lazzaretto, A., and Tsatsaronis, G., 2006, SPECO: Systematic and General Methodology for Calculating Efficiencies and Costs in Thermal Systems, Energy, Vol. 31, pp. 1257-1289.

Lozano, M., and Valero, A., 1993, Thermoeconomic Analysis of a Gas Turbine Cogeneration System, AES, Vol. 30, pp. 311-320.

Lozano, M. A., Valero, A., and Serra, L., 1993, Theory of Exergetic Cost and Thermoeconomic Optimization, Energy, Eds. Szargut, J., Kolenda, Z., Tsatsaronis, G., and Ziebik, A., Vol. 1, pp. 339-350.

Santos, J. J. C. S., 2009, On the Negentropy Application in Thermoeconomics, Itajubá, Doctoral Thesis, Mechanical Engineering Institute, Federal University of Itajubá.

Santos, J. J. C. S., do Nascimento, M. A. R., Lora, E. E. S., and Martínez Reyes, A. M., 2008b, On The Productive Structure for the Residues Cost Allocation in a Gas Turbine Cogeneration Plant, in: Proceedings of ECOS 2008, Vol. 2, pp. 641-648, Cracow, Poland.

Santos, J. J. C. S., do Nascimento, Lourenço, A. B., Silva, J. A. M., Donatelli, J. L., and Palacio, J. C. E., 2012, Exergy Disaggregation as an Alternative for System Disaggregation in Thermoeconomics, in: Proceedings of ECOS 2012, Perugia, Italy.

Santos, J. J. C. S., do Nascimento, M. A. R., Lora, E. E. S., and Martínez Reyes, A. M., 2008b, On the Productive Structure for the Residues Cost Allocation in a Gas Turbine Cogeneration Plant, in: Proceedings of ECOS 2008, Vol. 2, pp. 641-648, Cracow, Poland.

Tsatsaronis, G., and Pisa, J., 1994, Exergoeconomic Evaluation and Optimization of Energy System - Application to the CGAM Problem, Energy, Vol. 19, No. 3, pp. 287-321.

Torres, C., Serra, L., Valero, A., and Lozano, M. A., 1996, The Productive Structure and Thermoeconomic Theories of System Optimization,
ME’96: International Mechanical Engineering Congress \& Exposition, ASME WAN' 96.

Valero, A., Lozano, M. A., Serra, L., Tsatsaronis, G., Pisa, J., Frangopoulos, C., and von Spakovsky, M. R., 1994a, CGAM Problem: Definition and Conventional Solution, Energy, Vol. 19, No. 3, pp. 279-286.

Spakovsky, M. R., 1994, Application of Engineering Functional Analysis to the Analysis and Optimization of the CGAM Problem, Energy, Vol. 19, No. 3, pp. 343-364. 